
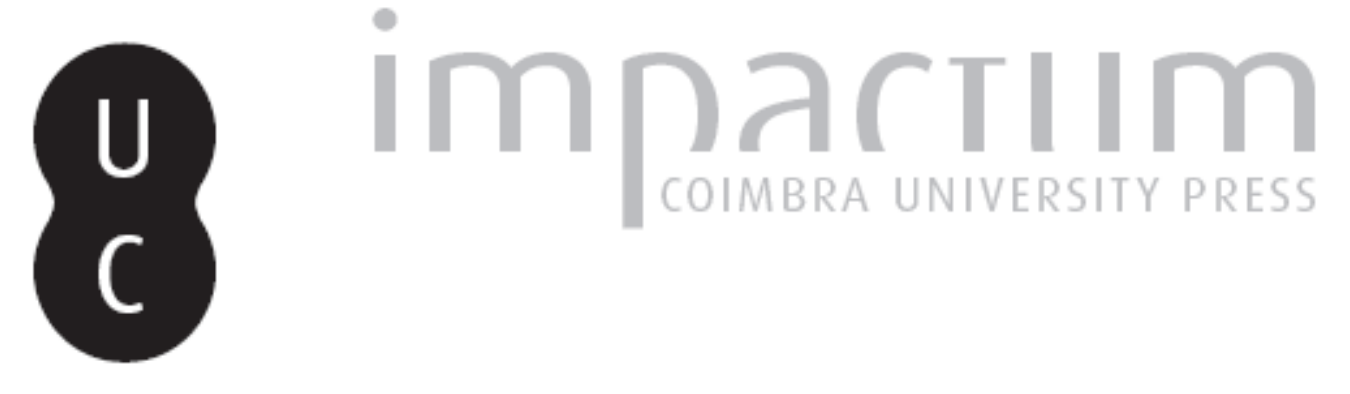

\title{
Riscos de secas em Portugal Continental
}

Autor(es): $\quad$ Pires, Vanda Cabrinha; Silva, Álvaro; Mendes, Luisa

Publicado por: Associação Portuguesa de Riscos, Prevenção e Segurança

URL persistente:

URI:http://hdl.handle.net/10316.2/36092

DOI:

DOI:http://dx.doi.org/10.14195/1647-7723_17_3

Accessed : $\quad$ 26-Apr-2023 14:45:47

A navegação consulta e descarregamento dos títulos inseridos nas Bibliotecas Digitais UC Digitalis, UC Pombalina e UC Impactum, pressupõem a aceitação plena e sem reservas dos Termos e Condições de Uso destas Bibliotecas Digitais, disponíveis em https://digitalis.uc.pt/pt-pt/termos.

Conforme exposto nos referidos Termos e Condições de Uso, o descarregamento de títulos de acesso restrito requer uma licença válida de autorização devendo o utilizador aceder ao(s) documento(s) a partir de um endereço de IP da instituição detentora da supramencionada licença.

Ao utilizador é apenas permitido o descarregamento para uso pessoal, pelo que o emprego do(s) título(s) descarregado(s) para outro fim, designadamente comercial, carece de autorização do respetivo autor ou editor da obra.

Na medida em que todas as obras da UC Digitalis se encontram protegidas pelo Código do Direito de Autor e Direitos Conexos e demais legislação aplicável, toda a cópia, parcial ou total, deste documento, nos casos em que é legalmente admitida, deverá conter ou fazer-se acompanhar por este aviso.

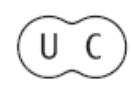




\section{territorium}

Riscos, Sociedade(s) e Segurança

Revista da Associação Portuguesa de Riscos, Prevenção e Segurança 2010 


\section{territorium 17, 2010, 27-34}

journal homepage: http://www.nicif.pt/riscos/Territorium/numeros_publicados

RISCOS DE SECAS EM PORTUGAL CONTINENTAL ${ }^{*}$

Vanda Cabrinha Pires

Instituto de Meteorologia

Divisão de Observação Meteorológica e Clima

vanda.cabrinha@meteo.pt

$\begin{array}{r}\text { Álvaro Silva } \\ \text { Instituto de Meteorologia }\end{array}$
Divisão de Observação Meteorológica e Clima
alvaro.silva@meteo.pt
Luisa Mendes
Divisão de Observação Meteorológica e Clima
Instituto de Meteorologia

RESUMO

Para se analisar qual o risco do fenómeno da seca em Portugal Continental foi efectuado um estudo que consistiu em caracterizar a evolução histórica das situações de seca no Continente através do índice meteorológico PDSI (PALMER, 1965), o qual detecta períodos de seca e os classifica em termos de sua intensidade.

Palavras chave: seca, PDSI, risco, intensidade.

\section{RÉSUMÉ}

Pour étudier le risque de sécheresse au Portugal continental, on a fait une caractérisation d'évolution historique de sécheresses avec l'index de sévérité de sécheresse Palmer Drought Severity Index - PDSI (PaLmer, 1965). Cet index permet de détecter des périodes de sécheresse et les classifier par son intensité.

Mots-clé: sécheresse, PDSI, risqué, intensité.

\section{ABSTRACT}

To study drought risk in Mainland Portugal, a characterization of droughts historical evolution was made, through Palmer Drought Severity Index - PDSI (PALMER, 1965) which allow us to detect drought periods and classifying them by the intensity.

Key words: drought, PDSI, risk, intensity.

$1^{*} \mathrm{O}$ texto deste artigo corresponde à comunicação apresentada ao V Encontro Nacional e I Congresso Internacional de Riscos e foi submetido para revisão em 28-05-2009, tendo sido aceite para publicação em 02-03-2010.

Este artigo é parte integrante da Revista Territorium, n. ${ }^{\circ} 17,2010$, (c Riscos, ISBN: 0872- 8941. 
Introdução

As situações de seca constituem uma ocorrência natural associada essencialmente à falta de precipitação, que se verifica todos os anos em diversas regiões do mundo.

A seca é o desastre natural de origem meteorológica e climatológica mais complexo e que afecta mais pessoas e durante mais tempo que qualquer outro.

O fenómeno da seca é diferente dos outros desastres naturais, os quais geralmente actuam de forma rápida e com impactos visíveis. O homem pode, no entanto, contribuir largamente para minimizar as consequências da seca através da deslocação de grandes quantidades de água ou promover o estabelecimento de mecanismos para o seu armazenamento; por outro lado, a má gestão do uso do solo e práticas agrícolas inadequadas contribuem para a degradação dos solos e dos recursos hídricos, aumentando a susceptibilidade a eventos de seca.

O clima caracteriza-se por uma permanente variabilidade que se verifica a todas as escalas temporais. Essa variabilidade, quando associada ao surgimento de fenómenos extremos como situações de chuvas intensas ou situações de seca dá origem à degradação do solo e à perda de vegetação (PIRES, 2003).

0 problema das secas deve enquadrar-se em anomalias da circulação geral da atmosfera, a que correspondem flutuações do clima numa escala local ou regional.

A situação geográfica do território de Portugal Continental é favorável à ocorrência de episódios de seca, quase sempre associados a situações de bloqueio em que o anticiclone subtropical do Atlântico Norte se mantém numa posição que impede que as perturbações da frente polar atinjam a Península Ibérica.

As situações de seca são frequentes em Portugal Continental, com consequências desastrosas na agricultura e na pecuária, nos recursos hídricos e no bem-estar das populações. Em particular as regiões a Sul do Tejo são as mais susceptíveis, e as mais afectadas.

\section{Metodologia}

Neste trabalho, cujo objectivo principal consiste em caracterizar a evolução histórica das situações de seca em Portugal Continental, utilizou-se o índice meteorológico PDSI - Palmer Drought Severity Index (PALMER, 1965). Este índice meteorológico (PDSI) detecta períodos de seca e classifica-os em termos da sua intensidade (PIRES, 2003). O acompanhamento mensal deste índice (ou em escalas temporais mais curtas) dá uma boa indicação da evolução inicial da seca, assim como, a avaliação da sua intensidade e duração. 0 cálculo do índice PDSI baseiase no conceito do balanço da água tendo em conta dados da quantidade de precipitação, temperatura do ar e capacidade de água disponível no solo; permite detectar a ocorrência de períodos de seca e classifica-os (QUADRo I) em termos de intensidade (fraca, moderada, severa e extrema) (PALmer, 1965).

QUADRo I - Classificação para períodos secos/chuvosos do índice PDSI (PALMER, 1965).

\begin{tabular}{|c|c|}
\hline Categoria & Classificação PDSI \\
\hline Chuva extrema & 4.00 ou superior \\
\hline Chuva severa & 3.00 a 3.99 \\
\hline Chuva moderada & 2.00 a 2.99 \\
\hline Chuva fraca & 0.50 a 1.99 \\
\hline Normal & -0.49 a 0.49 \\
\hline Seca fraca & -0.50 a -1.99 \\
\hline Seca moderada & -2.00 a -2.99 \\
\hline Seca severa & -3.00 a 3.99 \\
\hline Seca extrema & -4.00 ou inferior \\
\hline
\end{tabular}

A caracterização das situações de seca em Portugal Continental consistiu em: 1) analisar as séries longas do índice PDSI entre 1901-2006 para 4 estações meteorológicas Porto, Lisboa, Évora e Beja; 2) analisar a evolução do PDSI; 3) identificar períodos de seca; 4) identificar as situações de seca entre 1941-2006 com base em 35 estações meteorológicas de Portugal Continental; 5) comparar as secas com maior intensidade e duração.

As estações utilizadas e respectivos períodos constam do QUADRO II.

QuADro II - Estações meteorológicas e período utilizado.

\begin{tabular}{|ll|c|l|l|l|l|l|c||}
\hline N. $^{\circ}$ & Estações & Período & N. $^{\circ}$ & Estações & Período & N. $^{\circ}$ & Estações $^{\text {Período }}$ \\
\hline 174 & Alcácer do Sal & $1941-2006$ & 235 & Elvas & $1941-2006$ & 055 & Pinhão & $1941-2006$ \\
183 & Alvalade & $1941-2006$ & 557 & Évora & $1941-2006$ & 571 & Portalegre & $1941-2006$ \\
212 & Alvega & $1956-2006$ & 554 & Faro & $1965-2006$ & 279 & P. Rocha & $1941-2006$ \\
250 & Amareleja & $1963-2006$ & 134 & Fonte Boa & $1943-2006$ & 546 & Porto & $1941-2006$ \\
105 & Anadia & $1941-2006$ & 082 & Guarda & $1941-2006$ & 052 & Régua & $1941-2006$ \\
562 & Beja & $1941-2006$ & 535 & Lisboa & $1941-2006$ & 538 & Sagres & $1952-2006$ \\
023 & Braga & $1941-2006$ & 263 & Mértola & $1941-2006$ & 170 & Setúbal & $1952-2006$ \\
575 & Bragança & $1941-2006$ & 035 & M. Douro & $1943-2006$ & 541 & Sines & $1971-2006$ \\
150 & C. da Roca & $1941-2006$ & 032 & Mirandela & $1941-2006$ & 543 & V. Castelo & $1970-2006$ \\
570 & Castelo Branco & $1941-2006$ & 005 & Monção & $1968-2006$ & 566 & Vila Real & $1941-2006$ \\
266 & V. R. Sto António & $1949-2006$ & 226 & Mora & $1961-2006$ & 075 & Viseu & $1941-2006$ \\
549 & Coimbra & $1941-2006$ & 568 & P. Douradas & $1941-2006$ & & & \\
\hline
\end{tabular}


Situações de seca desde 1901

\section{Evolução do Índice PDSI}

São analisadas séries longas do índice PDSI de 4 estações meteorológicas: Porto, Lisboa, Évora e Beja, de forma a identificar períodos e anos de seca durante o século XX e início do século XXI (QUADRo III).

QUADRo III - Estações com séries longas do índice PDSI.

\begin{tabular}{|c|c|c|c|}
\hline Estações & Periodo & Estações & Periodo \\
\hline Porto & $1922-2006$ & Evora & $1901-2006$ \\
\hline Lisboa & $1901-2006$ & Beja & $1901-2006$ \\
\hline
\end{tabular}

Na Fig. 1, apresenta-se a distribuição anual do PDSI para as 4 estações com séries longas. Verifica-se que os valores negativos dominam em relação aos valores positivos do índice, uma vez que existe maior área abaixo da linha do zero, o que indica uma maior frequência e duração de períodos secos do que chuvosos. A ocorrência de anos com os valores do PDSI nas classes de seca mais intensas (classificação de moderada ou superior) foi mais frequentes nos anos 40, 80, 90 e entre 2003-06. As duas situações de seca que atingiram os valores mais baixos do PDSI, classificadas como severa a extrema, ocorreram nos
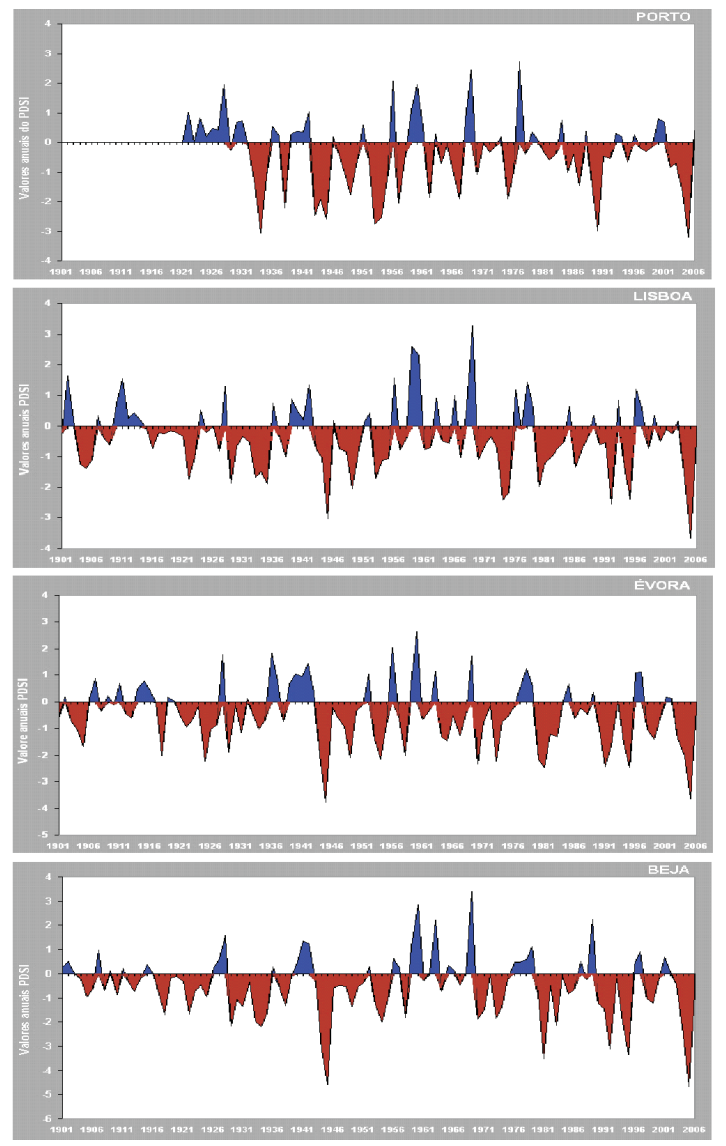

Fig. 1 - Valores anuais do índice de seca PDSI no Porto, Lisboa, Évora e Beja. anos de 1944 e 2005; acrescente-se, ainda, 1934, quando, no Porto, se verificou um ano de seca excepcional (PIRES, 2008).

\section{Identificação de Períodos de Seca}

No QuAdro IV são apresentadas as ocorrências de situações de seca para cada uma das séries longas, sendo ainda indicado, em cada uma das estações o número de situações de seca, sua duração (número de meses) e correspondentes anos de início e fim, intensidade e número de meses consecutivos nas classificações mais graves: severa e extrema (PIRES, 2008).

Verifica-se a ocorrência de um elevado número de secas em Beja, 28, seguido de Évora com 25, Porto com 23 e Lisboa com 21. Alguns episódios de seca destacamse, não só pela sua duração, mas também pelo número de meses consecutivos em situação de seca severa e extrema (QUADRo IV).

Em termos de duração há a realçar:

- 1933 -1935 no Porto (26 meses), Lisboa (15 meses) e Beja (28 meses)

- 1943 - 1946 no Porto (38 meses), Lisboa (26 meses), Évora e Beja (29 meses)

- 1953 -1955 no Porto (25 meses), Évora (23 meses) e Beja (24 meses)

- 1973 - 1976 em Lisboa (28 meses) e Évora (18 meses)

- 1979 - 1982 em Évora (33 meses)

- 1991 - 1992/3 em Lisboa e Beja (24 meses), Évora (18 meses)

- 1994 - 1995 em Lisboa (22 meses), Évora e Beja (20 meses)

- 2004 - 2006 em Beja, (33 meses), Évora, Lisboa e Porto (16 meses).

Em termos de intensidade (número de meses consecutivos em seca severa ou extrema) são de realçar:

- 12 meses - Beja, 1943-1946 e 1994-95

- 11 meses - Beja, 1994-1995

- 10 meses - Beja e Porto, 2004-2006

- 9 meses - Beja 1980-1981; Lisboa e Évora, 2004-2006 
Quadro IV - Anos de seca nas séries longas: Porto, Lisboa, Évora e Beja (Pires, 2008).

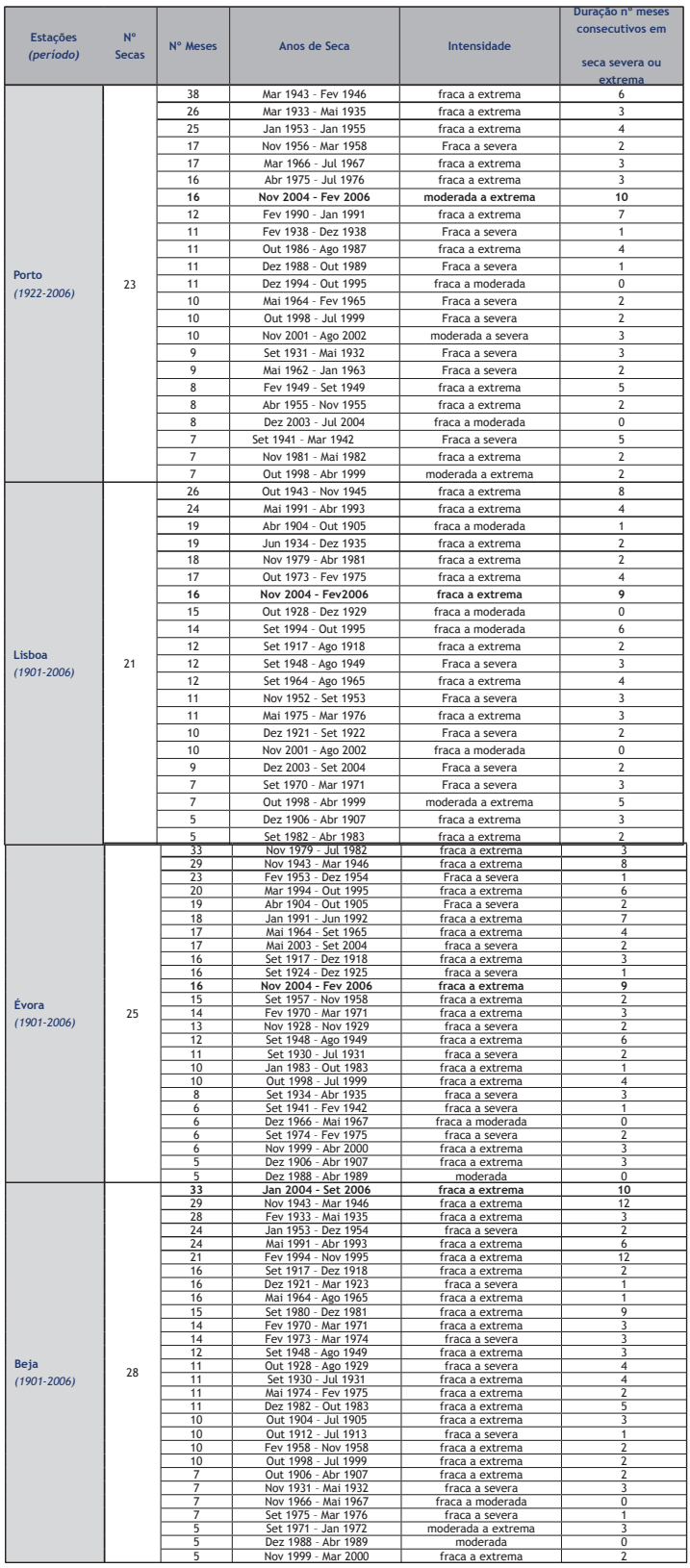

\section{Situações de seca no período 1941-2006}

\section{Identificação de episódios de seca}

Foram analisadas séries do índice PDSI de 35 estações meteorológicas no período 1941-2006, com o objectivo de identificar os episódios de seca e analisar a sua duração e intensidade.

$\mathrm{Na}$ classificação da seca em termos de intensidade utilizou-se o critério seguinte:

Seca fraca a moderada (o índice atinge estes dois valores)
Seca fraca a severa (a seca começa em seca fraca e vai até seca severa)

- Seca fraca a extrema (a seca começa em fraca e vai até seca extrema)

Seca fraca a extrema, mais de 4 meses consecutivos em seca severa e extrema

No Quadro V (PIRES, 2008) apresentam-se as situações de seca nas estações meteorológicas, segundo 2 regiões: 1 ) a norte do rio Tejo, subdividindo-a em interior Norte e Centro e litoral Norte e Centro, de modo a uma melhor caracterização espacial; 2) a Sul do rio Tejo.

Os anos que são identificados com seca não têm necessariamente de ser anos completos em situação de seca e quando existe uma barra preta a separar episódios de seca, significa que houve, pelo menos, 4 meses de interrupção.

Verifica-se, também, a ocorrência de períodos bem distintos de seca que abrangeram quase todo o território, sendo de destacar, pela sua duração e intensidade os seguintes: 1943-46, 1948-49, 1964-65, 1974-76, 1980-83, 1990-92, 1994-95, 1998-99, 2004-06.

QUADro V - Situações de seca entre 1941 e 2006 (PIREs, 2008).

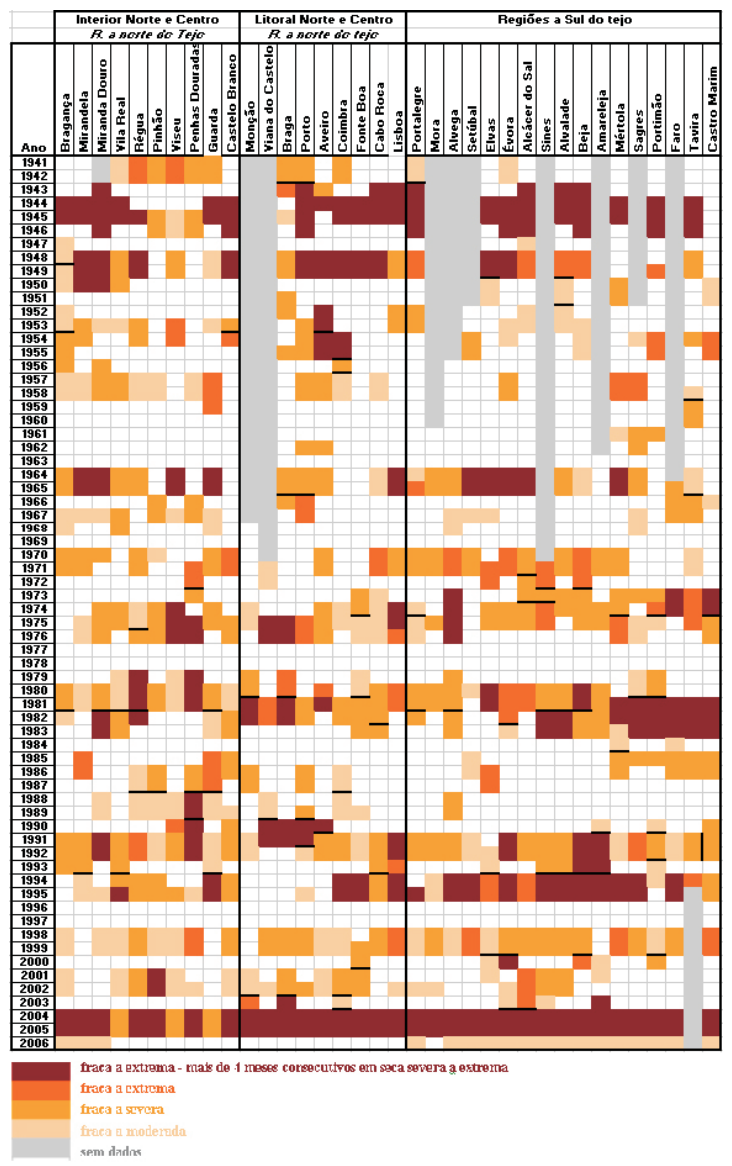


De salientar que as situações de seca foram muito frequentes nas décadas de 40 e 90 :

- 1941-42, 1943-46 e 1948-49

- 1991-92, 1994-95 e 1998-99

Verificaram-se ainda períodos mais curtos de seca e mais localizados, ou seja, menos abrangentes em termos territoriais: $1953-54$; 1957-58; 1970-71; 1985-86; 2001-02.

\section{Análise da frequência de ocorrência de secas}

JonEs et al. (1999) e KARL et al. (2000) identificaram, no século XX, dois períodos de aquecimento: 19101945 e desde 1976, intercalados por um período de arrefecimento, 1946-1975. Neste contexto, analisaramse as séries do índice PDSI de 24 estações nos períodos: a) 1941 a 1975, b) 1976 a 2006, de realçar, neste período, o aumento de temperatura média do ar e a diminuição da precipitação, em particular na Primavera.

No Quadro VI (PIRES, 2008) é apresentado o número de secas no período total de 1941-2006 e a percentagem de secas nos períodos de arrefecimento e aquecimento.

QUADRo VI - Número de ocorrência de secas entre 1941 e 2006 (Pires, 2008).

\begin{tabular}{|c|c|c|c|}
\hline $\begin{array}{l}\text { Estações } \\
(1941 \text { - } \\
2006)\end{array}$ & $\begin{array}{c}N^{\circ} \text { de situações } \\
\text { de seca } \\
1941-2006\end{array}$ & $\begin{array}{c}\text { Percentagem } \\
\text { de secas } \\
1941-1975\end{array}$ & $\begin{array}{c}\text { Percentagem } \\
\text { de secas } \\
1976-2006\end{array}$ \\
\hline Bragança & 16 & 62 & 38 \\
\hline Braga & 16 & 56 & 44 \\
\hline Mirandela & 14 & 57 & 43 \\
\hline M. Douro & 14 & 50 & 50 \\
\hline V. Real & 16 & 38 & 62 \\
\hline Pinhão & 17 & 41 & 59 \\
\hline Régua & 19 & 37 & 63 \\
\hline Porto & 20 & 45 & 55 \\
\hline Anadia & 16 & 56 & 44 \\
\hline Viseu & 16 & 38 & 62 \\
\hline Guarda & 15 & 53 & 47 \\
\hline P. Douradas & 17 & 42 & 58 \\
\hline Coimbra & 15 & 40 & 60 \\
\hline C. Branco & 19 & 32 & 68 \\
\hline Portalegre & 15 & 40 & 60 \\
\hline Elvas & 13 & 54 & 46 \\
\hline C. Roca & 15 & 40 & 60 \\
\hline Lisboa & 15 & 33 & 67 \\
\hline Évora & 18 & 44 & 56 \\
\hline Alcácer Sal & 15 & 47 & 53 \\
\hline Beja & 19 & 47 & 53 \\
\hline Alvalade & 14 & 50 & 50 \\
\hline Mértola & 18 & 39 & 61 \\
\hline $\begin{array}{l}\text { Praia } \\
\text { da Rocha }\end{array}$ & 17 & 29 & 71 \\
\hline
\end{tabular}

Comparativamente ao período total de 1941-2006, verifica-se que em $75 \%$ das estações meteorológicas consideradas, a percentagem de ocorrência de secas no período 1976-2006 é igual ou superior a 50\%. Exemplos que indicam bem esta situação são: Vila Real e Viseu (62\%), Castelo Branco (68\%), Lisboa (67\%), Mértola (61\%), Praia da Rocha (71\%).

Verifica-se que as situações de seca têm sido mais frequentes e mais intensas nos últimos 30 anos. De referir que nas duas últimas décadas do século $X X$, se observou uma intensificação da frequência de secas, em particular nos meses de Fevereiro a Abril (PIRES, 2003).

\section{Duração das secas}

Na Fig. 2, representa-se o número de meses em seca para cada um dos períodos identificados (PIRES, 2008). Verifica-se que as situações de seca de 1943-46, 1980-83, 1990-92 e 2004-06, são as que apresentam maior duração, com quase todo o território a apresentar mais de 18 meses em seca, sendo de destacar:

seca de 1943-46: 38 meses em Castelo Branco e no Porto; 30 meses em Portalegre;

seca de 1980-83: 39 meses em Alvega, 36 meses em Sagres, 35 meses em Faro;

seca de 1991-92: 34 meses em Penhas Douradas e Miranda do Douro com 30 meses;

seca de 2004-06: 36 meses em Braga, 35 meses em Amareleja e 33 em Beja;

Em termos de percentagem do território afectado, na seca de $1943-4652 \%$ do território esteve mais de 24 meses em situação de seca, enquanto nas secas de 198083 e 2004-06 a percentagem de território afectado foi de 27\% (Quadro VII).

Importante referir que depois da situação de seca de $1943-1946$ as secas mais longas ocorreram depois de 1980 (Quadro VII).

QUADRo VII - Percentagem de duração da seca em Portugal Continental. Período 1941-2006.

\begin{tabular}{|c|c|c|}
\hline Seca & mais de 24 meses & mais de 30 meses \\
\hline $1943-46$ & $52 \%$ & $11 \%$ \\
\hline $1980-83$ & $27 \%$ & $5 \%$ \\
\hline $2004-06$ & $27 \%$ & $2 \%$ \\
\hline $1990-92$ & $24 \%$ & $1 \%$ \\
\hline $1974-76$ & $2 \%$ & $0 \%$ \\
\hline $1994-95$ & $1 \%$ & $0 \%$ \\
\hline $1964-65$ & $1 \%$ & $0 \%$ \\
\hline $1948-49$ & $0 \%$ & $0 \%$ \\
\hline $1998-99$ & $0 \%$ & $0 \%$ \\
\hline
\end{tabular}


1943-46

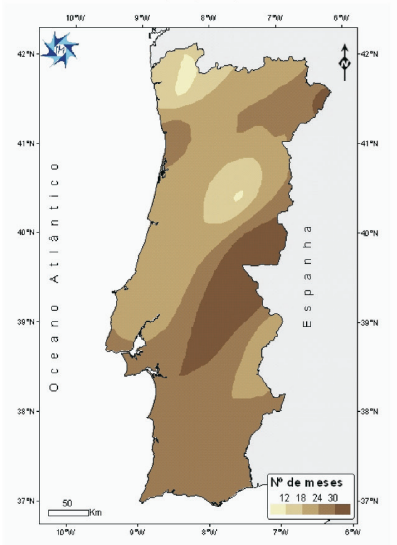

1974-76

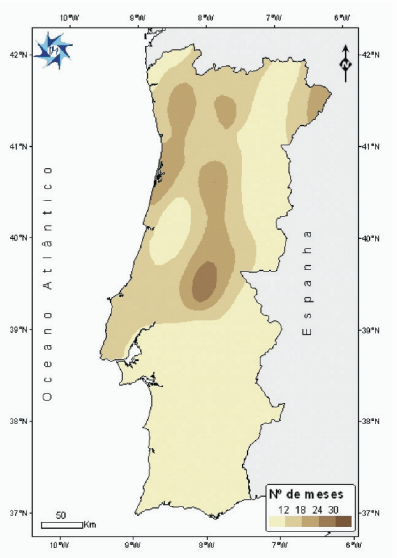

1994-95

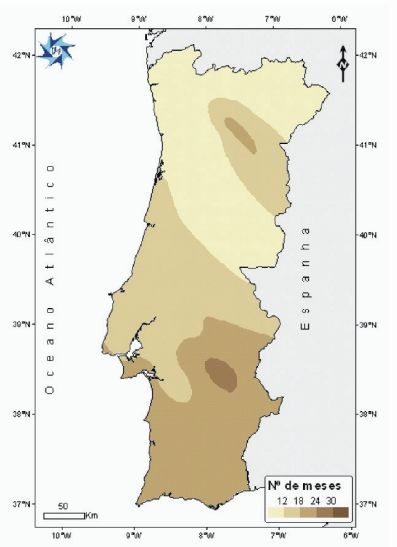

1948-49

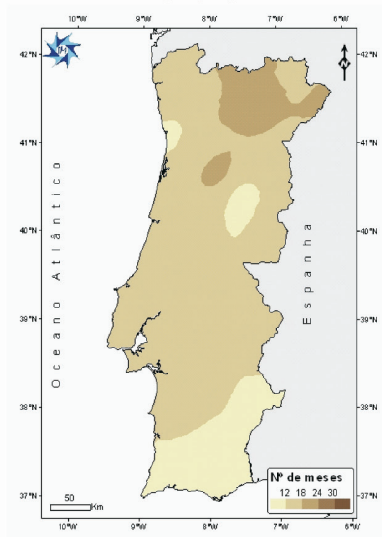

1980-83

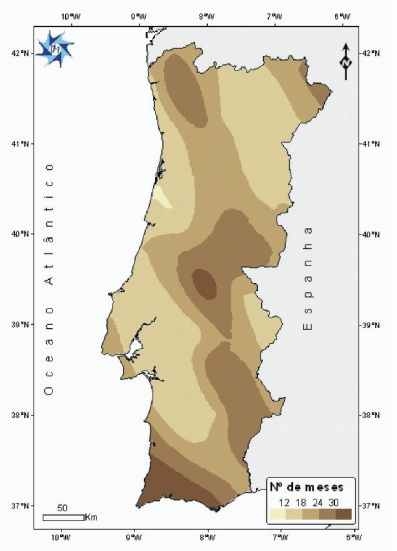

1998-99

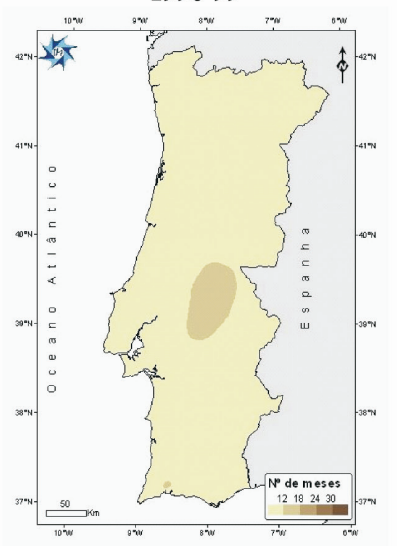

1964-65

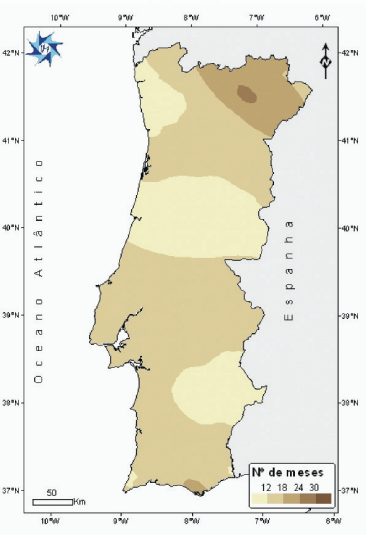

1990-92

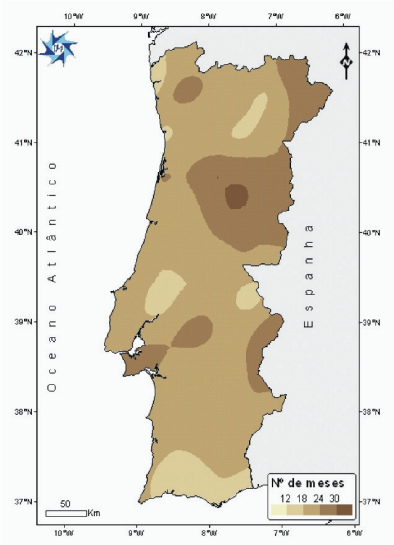

2004-06

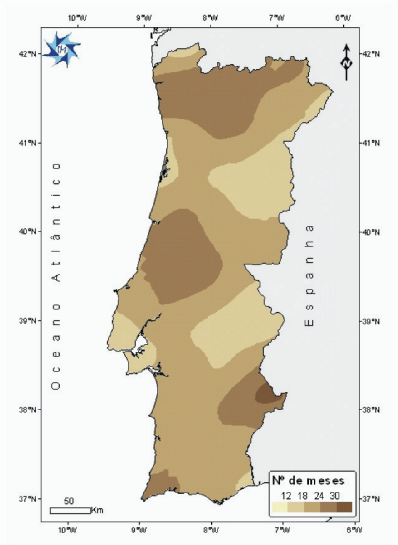

Fig. 2 - Representação espacial do número de meses em todas as classes de seca do índice PDSI nas situações de seca ocorridas desde 1941 (PIRES, 2008).

\section{Intensidade das secas}

Em cada um dos episódios identificados, analisou-se a severidade da seca de acordo com a classificação do PDSI. Na Fig. 3 (PIRES, 2008) é apresentado o número de meses consecutivos em seca severa e extrema para as secas de 1944-45, 1948-49, 1964-65, 1974-76, 1980-83, 1990-92, 1994-95 e 2004-06. Verifica-se que as secas mais graves em termos de intensidade foram as de 1943-46 e
2004-06. Na seca de 2004-06 grande parte do território esteve entre 7 e 9 meses consecutivos em situação de seca severa e extrema, sendo de destacar os 10 a 11 meses que se verificaram em muitas estações das regiões do litoral Norte, parte das regiões do Centro e região Sul. Em termos de percentagem na seca 2004-06, 34\% do território esteve mais de 9 meses consecutivos em seca severa e extrema, enquanto 1943-46 esteve apenas $22 \%$. Em termos médios, tanto $1943-46$ como $2004-06$ 


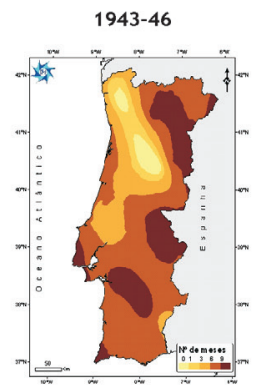

1974-76

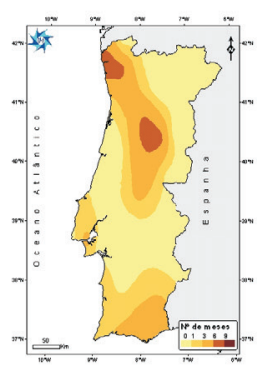

1994-95

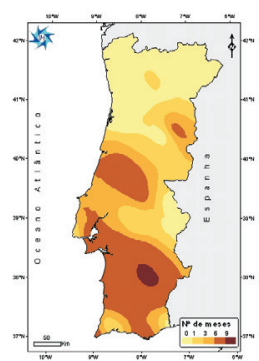

1948-49

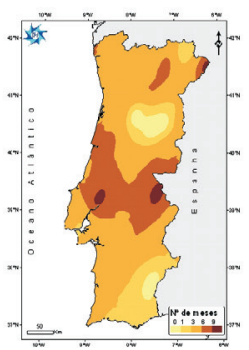

1980-83

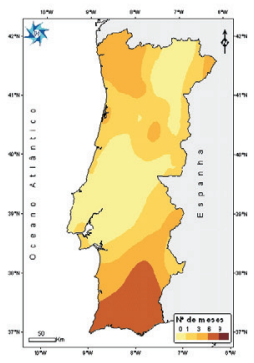

2004-06

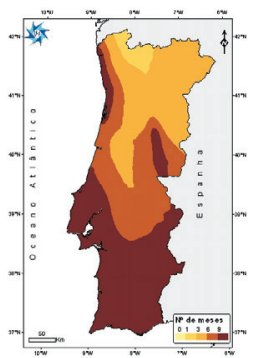

Fig. 3 - Representação espacial do número de meses nas classes de seca severa e extrema do índice PDSI nas situações de seca ocorridas desde 1941 (PIRES, 2008).

apresentam um número médio de meses consecutivos em seca severa e extrema de 7 meses. No entanto, 194346 apresenta uma menor percentagem do território em meses consecutivos de seca severa e extrema $(88 \%)$ em relação a 2004-06 com 100\% do território afectado (Fig. 4).

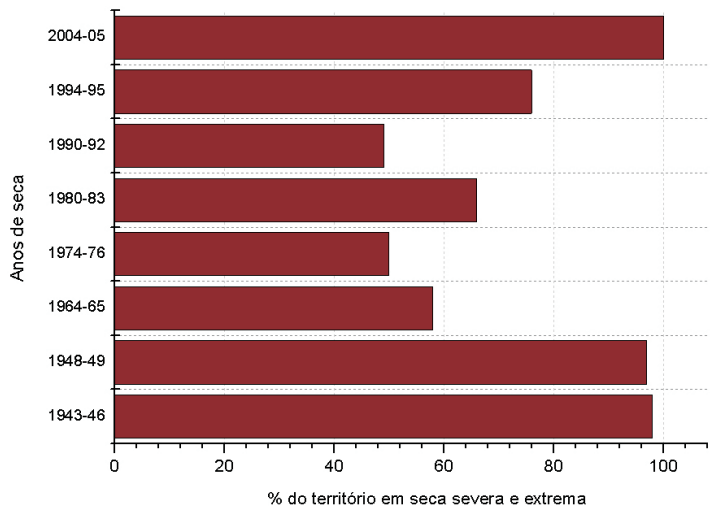

Fig. 4 - Percentagem do território afectado em seca severa e extrema em situações de seca identificadas no período de 1941 2006 (PIRES, 2008)
Deste modo pode-se afirmar que a seca 2004-06 foi a situação de seca mais intensa em termos de extensão territorial dos últimos 65 anos.

Considerando apenas duas áreas do território, a Norte e Sul do rio Tejo (Fig. 5) (PIRES, 2008), verifica-se que:

a) nas situações de seca de 1964-65, 1974-76 e 2004-06 as duas áreas foram de igual forma afectadas;

b) nas situações de seca de 1943-46, 1948-49 e 1990-92 foram mais afectadas as áreas a Norte do rio Tejo, em particular na de $1943-46$ com $72 \%$ de área afectada;

c) nas situações de seca de 1980-83, 1994-95 foram particularmente afectadas as áreas a Sul do rio Tejo.

\section{Conclusões}

As alterações climáticas que têm ocorrido ao nível do globo apontam não só para um aumento da temperatura média global, mas também para o aumento da 


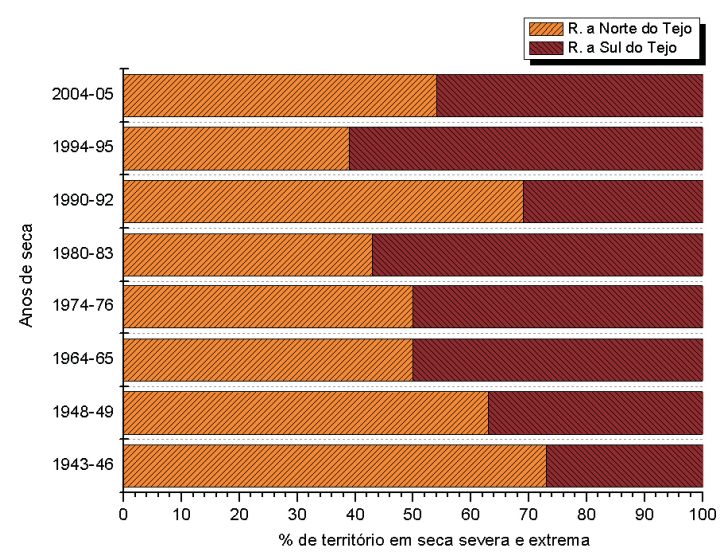

Fig. 5 - Percentagem do território em seca severa e extrema nas áreas a Norte do Tejo e a Sul do Tejo, em situações de seca identificadas no período de 1941-2006 (PIRES, 2008).

frequência e intensidade dos fenómenos climáticos extremos tais como secas, cheias, ondas de calor etc. Assim e relativamente às situações de seca em Portugal Continental há que destacar os seguintes pontos (PIREs, 2008):

a) Episódios de seca desde 1901

- Os valores do PDSI no período de arrefecimento, 1946-1975 são menos negativos que no período de aquecimento, depois de 1976, sugerindo um aumento da frequência de secas neste período;

- Verifica-se a ocorrência de um elevado número de secas em Beja (28), seguido de Évora com 25, Porto com 23 e Lisboa com 21.

b) Episódios de seca desde 1941

- Ocorreram 9 situações de seca entre 1941 e 2006: 1943-46; 1948-49; 1964-65; 1974-76;198083; 1990-92; 1994-95; 1998-99; 2004-06.

- Das 9 situações ocorridas as mais intensas e mais longas foram: 1943-46;1980-83;1990-92;199495; 2004-06.

- Décadas com mais situações de seca: 40 (194142, 1943-46 e 1948-49) e 90 (1991-92, 1994-95 e 1998-99).

- A seca 1943-46 foi a mais longa ocorrida nos últimos 65 anos, 1990-92 a $2^{\mathrm{a}}$ mais longa, 200406 e 1980-81 foram as $3^{\mathrm{a}}$ mais longas desde 1941. A destacar:

- Seca de 2004-06 foi a de maior extensão territorial (100\% do território afectado), seguida pela de 1943-46 (92\% do território);

- Seca 2004-06 foi a situação de seca mais intensa (meses consecutivos em seca severa e extrema) em termos de extensão territorial dos últimos 65 anos (100\%);

- Maior frequência de situações de secas nos últimos 30 anos (depois de 1976) quando comparado com o período entre 1941-1975.
- Em $75 \%$ das estações meteorológicas consideradas a percentagem de ocorrência de secas no período 1976-2006 é igual ou superior a $50 \%$.

Amaior frequência de situações de seca meteorológica que se verifica em Portugal Continental nas últimas décadas, é indicativo de um aumento do risco e da vulnerabilidade a este fenómeno, o que poderá obviamente trazer um aumento dos impactos, nomeadamente, ao nível dos sectores agrícola e hidrológico e necessariamente social.

\section{Referências bibliográficas}

Domingos, Sónia (2006) - Análise do índice de seca Standardized Precipitation Index (SPI) em Portugal Continental. Palmer Drought Severity Index (PDSI) versus SPI. Dissertação para a obtenção do grau de licenciatura em Meteorologia, Oceanografia e Geofísica Interna - variante Meteorologia. Lisboa, Faculdade de Ciências da Universidade de Lisboa, 51 p.

Jones, Phil.; New, M.; Parker, D.E.; Martin, S.; Rigor, I. (1999) - "Surface air temperature and its change over the past 150 years". Review of Geophysics, 37, p. 173-199.

Thomas, Karl; KINGHT, R.W.; BAKER, B. (2000) - "The record breaking global temperature of 1997 and 1998: evidence for an increase in the rate of global warming?" Geophysical Research Letters, 27, p. 719-722.

Palmer, Wayne (1965) - “Meteorological Drought”. US Weather Bureau Res. Paper 45, 58 p.

PIRES, Vanda (2003) - Frequência e Intensidade de Fenómenos meteorológicos extremos associados a precipitação. Dissertação para a obtenção do grau de Mestre em Ciências e Engenharia da Terra. Lisboa, Faculdade de Ciências da Universidade de Lisboa, 98 p.

PIRES, Vanda (2004) - "Evolução histórica do índice de Palmer (PDSI) em Portugal Continental". Monografia de Meteorologia e Geofísica, 47. Lisboa, Instituto de Meteorologia, 15 p.

PIRES, Vanda (2008) - "Análise das secas em Portugal Continental". Monografia de Meteorologia e Geofísica, 49, Lisboa, Instituto de Meteorologia, $15 \mathrm{p}$.

Szalal, Sandor; Szinel, C.S.; Zoвokı, J. (2000) - "Drought Monitoring in Hungary". Proceedings of an expert group meeting on Early Warning Systems for Drought Preparedness and Drought Management, OMM, p.161-176. 